\title{
Maintenance Expenditures and Indeterminacy under Increasing Returns to Scale*
}

\author{
Jang-Ting Guo \\ University of California, Riverside ${ }^{\dagger}$
}

\author{
Kevin J. Lansing \\ Federal Reserve Bank of San Francisco ${ }^{\ddagger}$
}

August 2, 2005

\begin{abstract}
This paper develops a one-sector real business cycle model in which competitive firms allocate resources for the production of goods, investment in new capital, and maintenance of existing capital. Firms also choose the utilization rate of existing capital. A higher utilization rate leads to faster capital depreciation, while an increase in maintenance activity has the opposite effect. We show that as the equilibrium ratio of maintenance expenditures to GDP rises, the required degree of increasing returns for local indeterminacy declines over a wide range of parameter combinations. When the model is calibrated to match empirical evidence on the relative size of maintenance and repair activity, we find that local indeterminacy (and belief-driven fluctuations) can occur with a mild and empirically-plausible degree of increasing returns - around 1.08.
\end{abstract}

Keywords: Indeterminacy, Maintenance and Repair, Capital Utilization, Real Business Cycles.

JEL Classification: E30, E32.

\footnotetext{
* An earlier version of this paper was titled "Maintenance Labor and Indeterminacy under Increasing Returns to Scale." For helpful comments and suggestions, we thank Sharon Harrison, Takashi Kamihigashi, Qinglai Meng, Kazuo Mino, Tomoyuki Nakajima, Kazuo Nishimura, Kazuo Shimomura, Ping Wang, Chong-Kee Yip, seminar participants at Academia Sinica (Taiwan), National Taiwan University, Chinese University of Hong Kong, Feng-Chia University (Taiwan), the Spring 2005 Midwest International Economics and Economic Theory Meetings, Kobe University, Kyoto University, and Osaka University. Of course, we take full responsibility for any errors.

† Corresponding author. Department of Economics, 4128 Sproul Hall, University of California, Riverside, CA, 92521-0427, (951) 827-1588, Fax: (951) 827-5685, e-mail: guojt@ucr.edu.

$\ddagger$ Research Department, Federal Reserve Bank of San Francisco, P.O. Box 7702, San Francisco, CA 941207702, (415) 974-2393, Fax: (415) 977-4031, e-mail: kevin.j.lansing@sf.frb.org.
} 


\section{Introduction}

Considerable progress has been made over the last decade in understanding the conditions needed to generate equilibrium indeterminacy in real business cycle (RBC) models with productive externalities or monopolistic competition. In the original one-sector models of Benhabib and Farmer (1994) and Farmer and Guo (1994), local indeterminacy requires an implausibly high degree of increasing returns-to-scale in production (Burnside, 1996; Basu and Fernald, 1997). Subsequent research has shown that RBC models with multiple sectors of production (Benhabib and Farmer, 1996; Perli, 1998; Weder, 2000; Harrison, 2001) or endogenous capital utilization (Wen, 1998) can generate local indeterminacy with much lower degrees of increasing returns. ${ }^{1}$ Interestingly, however, a combination model that incorporates both multiple production sectors and endogenous capital utilization may give rise to equilibrium indeterminacy only within an extremely narrow range of increasing returns. ${ }^{2}$

In this paper, we examine a straightforward extension of the one-sector, endogenous capital utilization model of Wen (1998). The extended model allows competitive firms to allocate resources for the production of goods, investment in new capital, and maintenance of existing capital. Following the original formulation of Greenwood, Hercowitz, and Huffman (1988), firms also choose the utilization rate of existing capital. A higher utilization rate leads to faster capital depreciation, while an increase in maintenance activity has the opposite effect. Maintenance activity is indexed by the "maintenance cost rate," defined as goods expenditures on maintenance per unit of installed capital. In our setup, the elasticity of the depreciation rate with respect to the maintenance cost rate is governed by a single parameter. The value of this parameter influences the equilibrium ratio of maintenance expenditures to GDP. When the elasticity parameter is set equal to zero, we recover the model of Wen (1998).

Our analysis is motivated by the work of McGrattan and Schmitz (1999) who argue that maintenance and repair activity is "too big to ignore." Using some unique survey data for Canada, these authors find that expenditures devoted to maintenance and repair of existing equipment and structures averaged 6.1 percent of GDP from 1961 to 1993. By comparison, expenditures on new equipment and structures averaged about 20 percent of the country's GDP over the same period. McGrattan and Schmitz (1999) also find that (detrended) maintenance and repair expenditures in Canada are strongly procyclical, exhibiting a correlation coefficient

\footnotetext{
${ }^{1}$ With the noted exceptions of Benhabib and Nishimura (1998), and Benhabib, Meng, and Nishimura (2000), among others, most studies in this literature postulate constant returns-to-scale at the individual firm level. We maintain this assumption throughout our analysis.

${ }^{2}$ In particular, the combination model of Guo and Harrison (2001) exhibits local indeterminacy only when the degree of increasing returns lies within the narrow range 1.021 to 1.026.
} 
with GDP of 0.89 .

In our model, households supply labor hours, taking the real wage as given. Firms, which are owned by households, make decisions about the amount of labor hours devoted to production, the level of expenditures devoted to investment and maintenance, and the utilization rate of existing capital. Firms act in the best interests of households to maximize a discounted stream of profits. Realized profits are paid out to households each period in the form of dividends. The production technology employed by firms is subject to an external effect that depends on the economy-wide average levels of utilized capital and labor inputs. Given our assumption of a Cobb-Douglas production technology, the equilibrium ratio of maintenance expenditures to GDP is constant. This result implies that maintenance expenditures are procyclical and perfectly correlated with output.

Using the standard procedure of log-linearizing the equilibrium conditions around the steady state, we derive analytical expressions for the trace and determinant of the Jacobian matrix that governs the model's local dynamics. From these expressions, we construct a two-dimensional plot that depicts the stability properties of the steady state as a function of the externality parameter (which governs the degree of increasing returns) and the ratio of maintenance expenditures to GDP. At each point on the stability plot, the elasticity parameters that govern the depreciation technology are calibrated to maintain a steady-state depreciation rate of 2.5 percent per quarter - a commonly-used value in the RBC literature. We show that as the maintenance ratio rises, the required degree of increasing returns for local indeterminacy declines over a wide range of parameter values. When the maintenance ratio is calibrated to 6.1 percent to match the Canadian data noted above, we find that local indeterminacy can occur with a mild degree of increasing returns - around 1.08. In contrast, when the maintenance ratio is zero, as in Wen (1998), the required degree of increasing returns for local indeterminacy is around 1.1. If we use the Canadian data to make inferences about the relative size of maintenance and repair activity in the U.S. economy, then the threshold for local indeterminacy in our model is clearly within the range of empirical plausibility. For example, Basu and Fernald (1997) obtain a returns-to-scale estimate for the U.S. private business economy of 1.03 (standard error $=0.18$ ), after controlling for reallocation of inputs across industries. ${ }^{3}$

As the maintenance ratio continues to rise, more of the firm's resources are devoted to maintaining existing capital rather than investing in new capital. Eventually, the firm's postmaintenance resources are no longer sufficient to finance new capital investment. In particular,

\footnotetext{
${ }^{3}$ See Basu and Fernald (1997, Table 3, col. 1, p. 268).
} 
when the maintenance ratio approaches the non-labor share of GDP (30 percent under our calibration), the required degree of increasing returns for local indeterminacy bottoms out and starts increasing asymptotically.

The intuition for why maintenance activity can make equilibrium indeterminacy easier to obtain is straightforward. If agents become optimistic about next period's return on capital, then the firm will invest more today, thus raising next period's capital stock. To validate agents' optimistic expectations as a self-fulfilling equilibrium, we require next period's return on capital, net of depreciation, to actually increase. Put another way, the necessary condition for local indeterminacy is that the net return on capital is an increasing function of the capital stock in equilibrium. In a one-sector RBC model with a constant capital utilization rate, the necessary condition can only be satisfied with very strong increasing returns. ${ }^{4}$ In the model of Wen (1998), the procyclical response of the capital utilization rate provides a direct boost to the gross return on capital during a belief-driven expansion. However, the more-intensive utilization rate also leads to faster depreciation, which serves to lower the net return on capital. It turns out that the first effect dominates the second effect so that the necessary condition for local indeterminacy can be satisfied with a milder degree of increasing returns relative to an otherwise identical model with constant utilization. In our model, the impact of higher capital utilization on depreciation is mitigated by the procyclical response of maintenance activity. By limiting the equilibrium increase in the depreciation rate, maintenance activity serves to boost the net return on capital, thus allowing the necessary condition for local indeterminacy to be satisfied with a milder degree of increasing returns.

Before laying out the details of our model and the quantitative results, we briefly mention some other related research. Licandro and Puch (2000) allow for maintenance activity and endogenous capital utilization in a model with constant returns-to-scale. In their model, however, the form of the depreciation technology causes equilibrium maintenance activity to be countercyclical - a result that is not consistent with the Canadian data noted above. Collard and Kollintazas (2000) construct an RBC model where the depreciation rate depends on labor hours devoted to maintenance. Our model follows the approach of McGrattan and Schmitz (1999) where depreciation depends on goods expended on maintenance services. Collard and Kollintazas also model the capital utilization rate as an increasing function of labor hours devoted to the production of goods - a "depreciation-in-use" effect. Our model follows the approach of Greenwood, Hercowitz, and Huffman (1988) and Wen (1998) by treating capital

\footnotetext{
${ }^{4}$ In the one-sector models of Benhabib and Farmer (1994) and Farmer and Guo (1994), the required degree of increasing returns for local indeterminacy is around 1.5.
} 
utilization as an independent choice variable. A recent paper by Pintus (2004) develops a model where the depreciation rate depends on an index of labor quality which he interprets as the rate of labor utilization. Labor quality/utilization is specified as an increasing, concave function of the real wage. The author shows that, for any degree of increasing returns, the presence of endogenous labor utilization reduces the range of capital-labor substitution elasticities over which local indeterminacy can occur. Aside from some basic model differences, our setup differs in that the depreciation rate depends on the maintenance cost rate, which is different from labor utilization. Moreover, our use of a standard Cobb-Douglas production technology imposes a unitary elasticity of substitution between capital and labor inputs.

The remainder of the paper is organized as follows. Section 2 describes the model. Section 3 examines the model's local dynamics and presents some quantitative analysis. Section 4 concludes.

\section{The Model}

We introduce endogenous maintenance activity into a decentralized version of the model of Wen (1998). The decentralized economy consists of a representative household that supplies labor, taking the real wage as given. The household is the owner of a representative firm that makes decisions about production, investment, maintenance, and capital utilization.

\subsection{Households}

The economy is populated by a large number of identical, infinitely-lived households, each endowed with one unit of time, who choose sequences of consumption $c_{t}$ and total hours worked $n_{t}$ to maximize:

$$
E_{0} \sum_{t=0}^{\infty} \beta^{t}\left[\log \left(c_{t}\right)-\frac{A n_{t}^{1+\gamma}}{1+\gamma}\right], \quad A>0
$$

subject to the budget constraint

$$
c_{t}=w_{t} n_{t}+\pi_{t}
$$

where $\beta \in(0,1)$ is the discount factor, $\gamma \geq 0$ is the inverse of the intertemporal elasticity of substitution in labor supply, $w_{t}$ is the real wage, and $\pi_{t}$ represents profits paid out by the firm in the form of dividends.

The first-order condition for the household's optimization problem is given by

$$
A c_{t} n_{t}^{\gamma}=w_{t}
$$


which equates the household's marginal rate of substitution between consumption and leisure to the real wage.

\subsection{Firms}

There are a large number of identical competitive firms that act in the best interests of the household-owners to maximize a discounted stream of profits. Each firm is endowed with $k_{0}$ units of capital and produces a homogenous final good $y_{t}$ using the following Cobb-Douglas production technology:

$$
y_{t}=\bar{e}_{t}\left(u_{t} k_{t}\right)^{\alpha} n_{t}^{1-\alpha}, \quad 0<\alpha<1,
$$

where $u_{t}$ is the endogenous rate of capital utilization, $k_{t}$ is the firm's stock of physical capital (e.g., equipment and structures). The presence of $n_{t}$ in (4) shows that household labor hours are entirely allocated to the production of goods. The symbol $\bar{e}_{t}$ represents a productive externality that takes the form

$$
\bar{e}_{t}=\left(\bar{u}_{t} \bar{k}_{t}\right)^{\alpha \eta} \bar{n}_{t}^{(1-\alpha) \eta}, \quad \eta \geq 0,
$$

where $\bar{u}_{t} \bar{k}_{t}$ and $\bar{n}_{t}$ are the economy-wide average levels of utilized capital and production labor inputs. In a symmetric equilibrium, all firms take the same actions such that $k_{t}=\bar{k}_{t}, n_{t}=\bar{n}_{t}$, and $u_{t}=\bar{u}_{t}$, for all $t$. As a result, equation (5) can be substituted into equation (4) to obtain the following aggregate production technology that may display increasing returns-to-scale:

$$
y_{t}=\left[\left(u_{t} k_{t}\right)^{\alpha} n_{t}^{1-\alpha}\right]^{1+\eta},
$$

where the degree of increasing returns is given by $1+\eta$. When $\eta=0$, the model collapses to the standard $\mathrm{RBC}$ formulation with constant returns-to-scale at both the firm and aggregate levels.

The law of motion for the capital stock is given by

$$
k_{t+1}=\left(1-\delta_{t}\right) k_{t}+i_{t}, \quad k_{0} \text { given, }
$$

where $\delta_{t} \in(0,1)$ is the endogenous capital depreciation rate and $i_{t}$ is investment in new capital. We postulate that $\delta_{t}$ takes the form

$$
\delta_{t}=\tau \frac{u_{t}^{\theta}}{\left(m_{t} / k_{t}\right)^{\phi}}, \quad \tau>0, \theta>1, \text { and } \phi \geq 0,
$$

where $m_{t}$ represents goods expenditures on maintenance. The intensity of maintenance activity is indexed by $m_{t} / k_{t}$, which is defined as the "maintenance cost rate." 5 The parameter $\phi$ is the

\footnotetext{
${ }^{5}$ This terminology follows Licandro and Puch (2000).
} 
elasticity of the depreciation rate with respect to the maintenance cost rate. When $\phi>0$, an increase in maintenance activity serves to slow the depreciation rate. In contrast, an increase in the capital utilization rate $u_{t}$ serves to accelerate the depreciation rate. Equation (8) implies $\partial^{2} \delta_{t} /\left[\partial u_{t} \partial\left(m_{t} / k_{t}\right)\right]<0$ so that an increase in maintenance activity reduces the marginal depreciation impact of a higher utilization rate. When $\phi=0$, we recover the model of Wen (1998). When $\theta \rightarrow \infty$, the model collapses to one with constant depreciation and utilization rates, as in Benhabib and Farmer (1994) and Farmer and Guo (1994).

Under the assumption that the labor market is perfectly competitive, firms take $w_{t}$ as given and choose sequences of $n_{t}, u_{t}, m_{t}$, and $k_{t+1}$, to maximize the following discounted stream of expected profits:

$$
E_{0} \sum_{t=0}^{\infty} \beta^{t}\left(1 / c_{t}\right) \underbrace{\left[y_{t}-w_{t} n_{t}-i_{t}-m_{t}\right]}_{\pi_{t}},
$$

subject to the firm's production function (4), the law of motion for capital (7), and the depreciation technology (8). Firms act in the best interests of households such that realized profits in period $t$ are valued using the household's marginal utility of consumption, given by $1 / c_{t}$.

The firm's first-order conditions with respect to the indicated variables are

$$
\begin{aligned}
n_{t}: & (1-\alpha) \frac{y_{t}}{n_{t}}=w_{t}, \\
u_{t}: & \frac{\alpha}{\theta} \frac{y_{t}}{k_{t}}=\delta_{t}, \\
m_{t}: & 1=\phi \frac{\delta_{t} k_{t}}{m_{t}} \\
k_{t+1}: & \frac{1}{c_{t}}=E_{t}\left\{\frac{\beta}{c_{t+1}}\left[\alpha \frac{y_{t+1}}{k_{t+1}}+1-(1+\phi) \delta_{t+1}\right]\right\},
\end{aligned}
$$

together with the transversality condition $\lim _{t \rightarrow \infty} \beta^{t}\left(k_{t+1} / c_{t}\right)=0$. Equation (10) shows that the firm hires labor to the point where the marginal product of labor is equal to the real wage. Equation (11) shows that the firm utilizes capital to the point where the marginal benefit of more output is equal to the marginal cost of faster depreciation. Equation (12) shows that the firm undertakes maintenance activity to the point where one unit of goods devoted to maintenance is equal to the marginal reduction in the firm's depreciation expense. Finally, equation (13) shows that the standard intertemporal consumption Euler equation is modified 
to reflect the depreciation impact of future capital-induced changes in the maintenance cost rate, as captured by the term $(1+\phi) \delta_{t+1}$.

From equation (11), we have $\delta_{t} k_{t}=(\alpha / \theta) y_{t}$ which can be substituted into (12) to obtain $m_{t}=(\phi \alpha / \theta) y_{t}$. Hence, in equilibrium, the firm allocates a constant fraction of total resources to maintenance. This implies that maintenance expenditures are procyclical and perfectly correlated with output. The procyclical behavior of maintenance activity in our model is qualitatively consistent with the empirical evidence documented by McGrattan and Schmitz (1999). These authors find that detrended expenditures for maintenance and repair activity in Canada exhibit a correlation coefficient with GDP of 0.89.

To obtain an expression for the reduced-form social technology as a function of $k_{t}$ and $n_{t}$, we use equations (8) and (11) to solve for $u_{t}$ and substitute the resulting expression into (6) to obtain

$$
y_{t}=B k_{t}^{\alpha_{k}} n_{t}^{\alpha_{n}}
$$

where the constants $B, \alpha_{k}$, and $\alpha_{n}$ represent the following combinations of parameters:

$$
\begin{aligned}
B & =\left[\frac{\phi^{\phi}}{\tau}\left(\frac{\alpha}{\theta}\right)^{1+\phi}\right]^{\frac{\alpha(1+\eta)}{\theta-\alpha(1+\eta)(1+\phi)}}, \\
\alpha_{k} & =\frac{\alpha(1+\eta)(\theta-1-\phi)}{\theta-\alpha(1+\eta)(1+\phi)}, \\
\alpha_{n} & =\frac{(1-\alpha)(1+\eta) \theta}{\theta-\alpha(1+\eta)(1+\phi)} .
\end{aligned}
$$

We restrict our analysis to the case of $\alpha_{k}<1$, which implies that the productive externality is not strong enough to generate sustained endogenous growth. We further confine our attention to the regions of the parameter space where $\theta-1-\phi>0$ to guarantee that $\alpha_{k}>0$. Equations (16) and (17) together imply the result $\partial\left(\alpha_{k}+\alpha_{n}\right) / \partial \phi>0$ whenever $\eta>0$. Therefore, an increase in the depreciation elasticity parameter $\phi$ brings about a larger effective degree of aggregate increasing returns in comparison to the $\phi=0$ case considered by Wen (1998). When $\eta=0$, we have $\alpha_{k}+\alpha_{n}=1$ for any given value of $\phi$. Thus, when the productive externality vanishes, the model exhibits constant returns-to-scale in production. ${ }^{6}$

\footnotetext{
${ }^{6}$ This condition ensures that the individual firm's decision problem is concave.
} 


\section{Analysis of Dynamics}

By combining equations (3), (10), and (14), the equilibrium quantity of labor hours can be written as

$$
n_{t}=\left[\frac{(1-\alpha) B}{A} \frac{k_{t}^{\alpha_{k}}}{c_{t}}\right]^{\frac{1}{1+\gamma-\alpha_{n}}},
$$

which is used to eliminate $n_{t}$ from the remaining equilibrium conditions. Proceeding in this manner and then log-linearizing the perfect-foresight versions of the equilibrium conditions around the unique interior steady state yields the following deterministic system:

$$
\left[\begin{array}{c}
\log \left(k_{t+1} / k\right) \\
\log \left(c_{t+1} / c\right)
\end{array}\right]=\underbrace{\left[\begin{array}{cc}
\lambda_{1} & \lambda_{2} \\
\frac{\lambda_{1} \lambda_{3}}{\lambda_{4}} & \frac{1+\lambda_{2} \lambda_{3}}{\lambda_{4}}
\end{array}\right]}_{\mathbf{J}}\left[\begin{array}{c}
\log \left(k_{t} / k\right) \\
\log \left(c_{t} / c\right)
\end{array}\right], \quad k_{0} \text { given, }
$$

where variables without subscripts represent steady-state values, and $\mathbf{J}$ is the Jacobian matrix of partial derivatives of the transformed dynamical system. The elements that make up the Jacobian matrix $\mathbf{J}$ are given by

$$
\begin{aligned}
& \lambda_{1}=1-\frac{\alpha_{k} \delta(1+\gamma)[\theta-\alpha(1+\phi)]}{\alpha\left(\alpha_{n}-1-\gamma\right)}, \\
& \lambda_{2}=\frac{\delta(1+\gamma)[\theta-\alpha(1+\phi)]}{\alpha\left(\alpha_{n}-1-\gamma\right)} \\
& \lambda_{3}=\frac{(1-\beta)\left[\left(1-\alpha_{k}\right)(1+\gamma)-\alpha_{n}\right]}{\alpha_{n}-1-\gamma}, \\
& \lambda_{4}=1-\frac{\alpha_{n}(1-\beta)}{\alpha_{n}-1-\gamma}
\end{aligned}
$$

where $\rho \equiv 1 / \beta-1$ is the household's rate of time preference, and $\delta=\rho /(\theta-1-\phi)$ is the steady-state depreciation rate. ${ }^{7}$ Notice that the elements of $\mathbf{J}$ do not depend on either the labor disutility parameter $A$ or the constant $\tau$ in the depreciation technology (8). The expressions for the determinant and trace of $\mathbf{J}$ are

$$
\begin{aligned}
\operatorname{det}(\mathbf{J}) & =\frac{\lambda_{1}}{\lambda_{4}}, \\
\operatorname{tr}(\mathbf{J}) & =\lambda_{1}+\frac{1+\lambda_{2} \lambda_{3}}{\lambda_{4}} .
\end{aligned}
$$

\footnotetext{
${ }^{7}$ The steady-state allocations are: $n=\{(1-\alpha) /[A-A \alpha(1+\phi) / \theta]\}^{1 /(1+\gamma)}, k=\left[B \alpha n^{\alpha_{n}} /(\theta \delta)\right]^{1 /\left(1-\alpha_{k}\right)}$, and $c=[1-\alpha(1+\phi) / \theta] B k^{\alpha_{k}} n^{\alpha_{n}}$.
} 


\subsection{Local Indeterminacy}

The local stability properties of the steady state are determined by comparing the number of eigenvalues of $\mathbf{J}$ located inside the unit circle with the number of initial conditions. There is one initial condition represented by $k_{0}$. Hence, if both eigenvalues of $\mathbf{J}$ lie inside the unit circle, then the steady state is indeterminate (a sink) and the economy is subject to belief-driven fluctuations. This will occur if and only if

$$
-1<\operatorname{det}(\mathbf{J})<1 \text { and }-[1+\operatorname{det}(\mathbf{J})]<\operatorname{tr}(\mathbf{J})<1+\operatorname{det}(\mathbf{J}) .
$$

We quantitatively investigate the local stability properties using standard parameter values. We choose $\alpha=0.3$ such that labor's share of output $(1-\alpha)$ is held fixed at 70 percent, as computed from equation (10). We choose $\beta=0.99$ to obtain a quarterly real interest rate of 1 percent. We choose $\gamma=0$ to reflect the commonly-used specification of "indivisible labor". Figure 1 depicts the stability properties of the steady state as a function of the externality parameter $\eta$ and the equilibrium maintenance-to-GDP ratio $m_{t} / y_{t}=\phi \alpha / \theta$. At each point on the stability plot, we calibrate the depreciation elasticity parameters $\phi$ and $\theta$ to achieve the desired maintenance ratio while holding the steady-state depreciation rate constant at 2.5 percent per quarter. Figure 2 plots the calibrated values of $\phi$ and $\theta$ as a function of the equilibrium maintenance ratio. When $\phi=0$, we have $\theta=1.4$, as in Wen (1998). As the maintenance share increases, higher values of $\phi$ and $\theta$ are required to achieve the target steady-state depreciation rate. $^{8}$

For any given values of $\phi$ and $\theta$ under our calibration, the most-binding condition among the necessary and sufficient conditions for local indeterminacy in (26) turns out to be $\operatorname{det}(\mathbf{J})$ $+\operatorname{tr}(\mathbf{J})>-1$. Using equations (24) and (25), this inequality condition can be transformed (after tedious algebra) into the following restriction on the externality parameter:

$$
\eta>\frac{\theta(1+\gamma)\{4 \alpha+\delta(1-\beta)[\theta-\alpha(1+\phi)]\}}{2 \alpha(1+\gamma)(1+\phi)\{2 \alpha+\delta[\theta-\alpha(1+\phi)]\}+\alpha \theta(1+\beta)\{2(1-\alpha)-\delta(1+\gamma)[\theta-\alpha(1+\phi)]\}}-1,
$$

where our calibration procedure holds $\delta$ fixed at 2.5 percent per quarter. We find that the minimum required value of $\eta$ for local indeterminacy from equation (27) is declining over a wide range of calibrations for the equilibrium maintenance ratio. This feature of the model is captured by the downward-sloping line that separates the regions labeled "Saddle" and "Sink" in Figure 1. As the equilibrium maintenance ratio increases along the $x$-axis, the minimum required value of $\eta$ for local indeterminacy can be read directly off the downward-sloping line.

\footnotetext{
${ }^{8}$ The formulas that govern the calibrated parameter values in Figure 2 are $\phi=s_{m}(\rho+\bar{\delta}) /\left[\left(\alpha-s_{m}\right) \bar{\delta}\right]$ and $\theta=\phi \alpha / s_{m}$, where $s_{m}$ is the desired equilibrium maintenance ratio and $\bar{\delta}=0.025$ is the target steady-state depreciation rate. These formulas yield the result $\theta-1-\phi=\rho / \bar{\delta}>0$, such that $\alpha_{k}>0$ from equation (16).
} 
When $m_{t} / y_{t}=0$ as in Wen (1998), Figure 1 shows that the model requires $\eta>0.1037$ for local indeterminacy. Given the lack of direct evidence on maintenance and repair activity in the U.S. economy, we infer the size of the U.S. maintenance-to-GDP ratio from the Canadian data documented by McGrattan and Schmitz (1999). When we set $\phi=0.3584$ and $\theta=1.7624$ such that $m_{t} / y_{t}=0.061$ to match the average maintenance ratio in Canada, the model requires $\eta>0.0826$ for local indeterminacy. This value corresponds to a mild degree of increasing returns, one that is not significantly different from the estimate of 1.03 (standard error $=0.18$ ) obtained by Basu and Fernald (1997) for the U.S. private business economy. Figure 1 also shows that the model is capable of lowering the threshold for the onset of local indeterminacy without suffering the drawback of narrowing the range of increasing returns over which local indeterminacy can occur, as happens in the two-sector, endogenous capital utilization model of Guo and Harrison (2001).

If we postulate a higher maintenance-to-GDP ratio in the U.S. economy than in Canada, then the minimum required value of $\eta$ for local indeterminacy can be pushed down even further. For example, when $m_{t} / y_{t}=0.10$, the model requires $\eta>0.070$ for local indeterminacy. As the equilibrium maintenance ratio continues to rise, the calibrated value of $\theta-1-\phi$ declines and we obtain a lower equilibrium elasticity of output with respect to capital $\alpha_{k}$ from equation (16). Intuitively, as more of the firm's resources are devoted to maintenance, less resources are available for investing in new capital. When $m_{t} / y_{t} \rightarrow \alpha=0.30$, the available resources for new investment become exhausted and an equilibrium is no longer feasible. As the upper bound on the maintenance ratio is approached, Figure 1 shows that the minimum required value of $\eta$ for local indeterminacy bottoms out and then starts increasing asymptotically.

When the maintenance ratio is below the maximum feasible value of 0.30 and the externality parameter $\eta$ exceeds the minimum value given by equation (27), the economy is subject to belief-driven fluctuations. Our numerical experiments with the model indicate that the business cycle responses to iid sunspot shocks or autocorrelated fundamental shocks are qualitatively similar to those documented by Wen (1998) and Benhabib and Wen (2004) for similar models without maintenance activity. This result is not surprising given that maintenance expenditures are a constant fraction of total output in equilibrium. ${ }^{9}$

\footnotetext{
${ }^{9}$ In two-sector RBC models with constant capital utilization (Benhabib and Farmer, 1996; Perli, 1998; Weder, 2000; Harrison, 2001), the required degree of increasing returns for local indeterminacy is also around 1.08. However, in contrast to the one-sector framework used here, these two-sector models yield the result that consumption moves countercyclically when economic fluctuations are driven solely by sunspot shocks.
} 


\subsection{Intuition}

To gain insight into the mechanism that generates local indeterminacy in our model, it is useful to compare the equilibrium elasticity of output with respect to labor $\alpha_{n}$ to the corresponding elasticity in some other benchmark models:

$$
\begin{array}{ll}
\text { Maintenance model } & \alpha_{n}=\frac{(1-\alpha)(1+\eta) \theta}{\theta-\alpha(1+\eta)(1+\phi)}, \\
\text { Wen (1998) } & \alpha_{n}=\frac{(1-\alpha)(1+\eta) \theta}{\theta-\alpha(1+\eta)}, \\
\text { Benhabib and Farmer (1994) } & \\
\text { Farmer and Guo (1994) } & \alpha_{n}=(1-\alpha)(1+\eta) .
\end{array}
$$

In each of the above models, the reduced-form social technology takes the form $y_{t}=$ $B k_{t}^{\alpha_{k}} n_{t}^{\alpha_{n}}$. It is well-known that a necessary (but not sufficient) condition for local indeterminacy in this class of one-sector RBC models is

$$
\alpha_{n}-1>\gamma
$$

which says that the equilibrium wage-hours locus is positively sloped $\left(\alpha_{n}>1\right)$ and steeper than the labor supply curve (which has slope $\gamma$ ). The above models differ with respect to their specification for $\alpha_{n}$, with the maintenance model subsuming the others as special cases. When $\phi=0$, the maintenance model is identical to that of Wen (1998). When $\theta \rightarrow \infty$, the maintenance model implies constant capital depreciation and utilization rates, as in Benhabib and Farmer (1994) and Farmer and Guo (1994). Comparing across models for any given values of $\alpha, \eta$, and $\theta$, we see that $\alpha_{n}$ will be highest for the maintenance model, thus making it easier to satisfy the indeterminacy condition (28).

Further insight can be gained by examining the following version of the consumption Euler equation that abstracts from uncertainty:

$$
\frac{c_{t+1}}{c_{t}}=\beta\left[\alpha \frac{y_{t+1}}{k_{t+1}}+1-(1+\phi) \delta_{t+1}\right] .
$$

In equation (29), next period's gross return on capital is given by $\alpha y_{t+1} / k_{t+1}+1$, whereas the return on capital net of depreciation is given by $\alpha y_{t+1} / k_{t+1}+1-(1+\phi) \delta_{t+1}$. If agents become optimistic about next period's return on capital, then the household/firm will sacrifice consumption today for more investment and higher future consumption, thereby lowering $c_{t}$ and raising $k_{t+1}$ and $c_{t+1}$. A higher value for $c_{t+1}$ combined with a lower value for $c_{t}$ causes the left-hand-side of (29) to increase. To validate agents' optimistic expectations as a self-fulfilling 
equilibrium, we require the right-hand-side of (29) to also increase, i.e., next period's return on capital, net of depreciation, must be an increasing function of $k_{t+1}$ in equilibrium.

When the capital utilization rate is constant, as in the Benhabib-Farmer-Guo model, we have $\delta_{t+1}=\delta$ for all $t$. Under this setup, very strong increasing are required to make the net return on capital an increasing function of $k_{t+1}$. In the endogenous capital utilization model of Wen (1998) with $\phi=0$, the procyclical response of the utilization rate $u_{t+1}$ provides a direct boost to the gross return on capital $\alpha y_{t+1} / k_{t+1}+1$ during a belief-driven expansion. However, a higher value of $u_{t+1}$ also leads to faster depreciation, which serves to lower the net return $\alpha y_{t+1} / k_{t+1}+1-\delta_{t+1}$. It turns out that the first effect dominates the second effect so that belief-driven fluctuations can occur with a milder degree of increasing returns relative to the Benhabib-Farmer-Guo model.

In our model, the presence of maintenance activity also has two effects. The first effect is the procyclical response of maintenance expenditures $m_{t+1}$. These expenditures serve to dampen the response of $\delta_{t+1}$ to belief-driven changes in $u_{t+1}$. The second effect works in the opposite direction. In particular, the higher value of $k_{t+1}$ that results from a belief-driven investment spurt pushes down the maintenance cost rate $m_{t+1} / k_{t+1}$. This effect is reflected by the term $(1+\phi) \delta_{t+1}$ in equation (29) that subtracts from the net return on capital. In equilibrium, the procyclical response of maintenance expenditures dominates the impact of a higher $k_{t+1}$ such that the maintenance cost rate is also procyclical. This feature of the model serves to further ease the conditions needed for equilibrium indeterminacy.

\section{Conclusion}

Maintenance and repair activity appears to be a quantitatively significant feature of modern industrial economies. Motivated by this observation, we introduce maintenance expenditures into a decentralized version of the one-sector, endogenous capital utilization model of Wen (1998). With this straightforward extension, we find that the threshold degree of increasing returns needed for local indeterminacy is a decreasing function of the equilibrium maintenanceto-GDP ratio in the relevant region of the parameter space. When the maintenance-to-GDP ratio is calibrated to 6.1 percent to match the evidence documented by McGrattan and Schmitz (1999), we find that local indeterminacy can occur with a mild and empirically-plausible degree of increasing returns - around 1.08. Moreover, achieving this lower threshold for the onset of local indeterminacy does not come at the expense of narrowing the range of increasing returns over which local indeterminacy can occur. 


\section{References}

[1] Basu, S. and J.G. Fernald. (1997). "Returns to Scale in U.S. Production: Estimates and Implications," Journal of Political Economy, 105, 249-283.

[2] Benhabib, J. and R.E.A. Farmer. (1994). "Indeterminacy and Increasing Returns," Journal of Economic Theory, 63, 19-41.

[3] Benhabib, J. and K. Nishimura. (1998). "Indeterminacy and Sunspots with Constant Returns," Journal of Economic Theory, 81, 58-96.

[4] Benhabib, J. Meng, Q., and K. Nishimura. (2000). "Indeterminacy under Constant Returns to Scale in Multisector Economies," Econometrica, 68, 1541-1548.

[5] Benhabib, J. and Y. Wen. (2004). "Indeterminacy, Aggregate Demand, and the Real Business Cycle," Journal of Monetary Economics, 51, 503-530.

[6] Burnside, C. (1996). "Production Function Regression, Returns to Scale, and Externalities," Journal of Monetary Economics, 37, 177-201.

[7] Collard, F. and T. Kollintzas. (2000), "Maintenance, Utilization, and Depreciation along the Business Cycle," CEPR Discussion Paper 2477.

[8] Farmer, R.E.A. and J.-T. Guo. (1994). "Real Business Cycles and the Animal Spirits Hypothesis," Journal of Economic Theory, 63, 42-72.

[9] Greenwood, J., Z. Hercowitz, and G.W. Huffman. (1988). "Investment, Capacity Utilization, and the Real Business Cycle, American Economic Review, 78, 402-417.

[10] Guo, J.-T. and S.G. Harrison (2001). "Indeterminacy with Capital Utilization and SectorSpecific Externalities," Economics Letters, 72, 355-360.

[11] Harrison, S.G. (2001). "Indeterminacy in a Model with Sector-Specific Externalities," Journal of Economic Dynamics and Control, 25, 747-764.

[12] Licandro, O., and L.A. Puch. (2000). "Capital Utilization, Maintenance Costs, and the Business Cycle," Annales D'Économie et de Statistique, 58, 143-164.

[13] McGrattan, E.R., and J.A. Schmitz, Jr. (1999). "Maintenance and Repair: Too Big to Ignore," Federal Reserve Bank of Minneapolis, Quarterly Review, 23 (4), 2-13.

[14] Perli, R. (1998). "Indeterminacy, Home Production, and the Business Cycle: A Calibrated Analysis," Journal of Monetary Economics, 41, 105-125.

[15] Pintus, P. (2004). "Expectations-Driven Fluctuations when Factor Utilization is Variable," Macroeconomic Dynamics, 8, 3-26.

[16] Weder, M. (2000). "Animal Spirits, Technology Shocks and the Business Cycle," Journal of Economic Dynamics and Control, 24, 273-295.

[17] Wen, Y. (1998). "Capacity Utilization Under Increasing Returns to Scale," Journal of Economic Theory, 81, 7-36. 
Fig. 1: Stability Properties of the Steady State

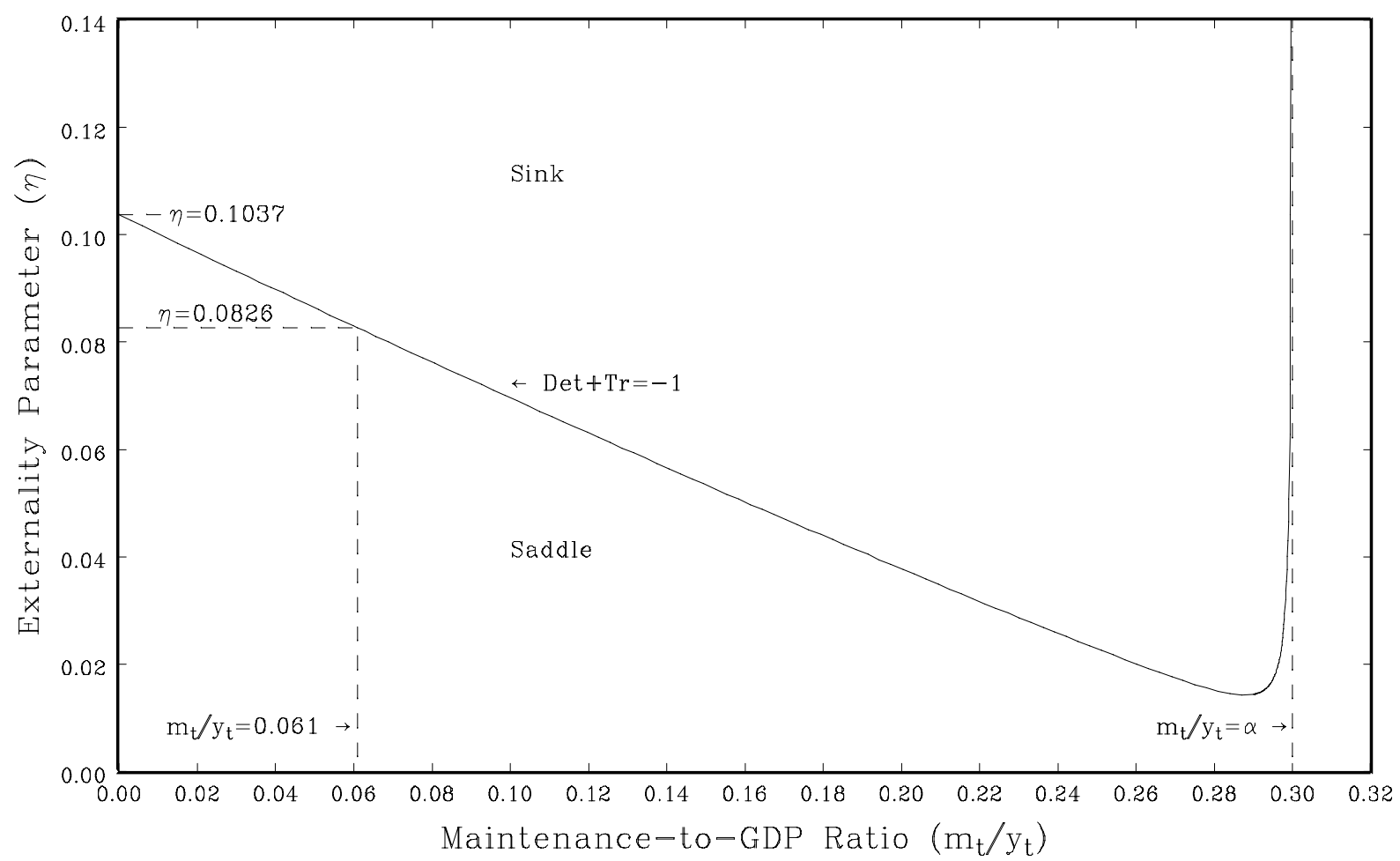

Fig. 2: Calibrated Parameter Values to Achieve $\delta=0.025$

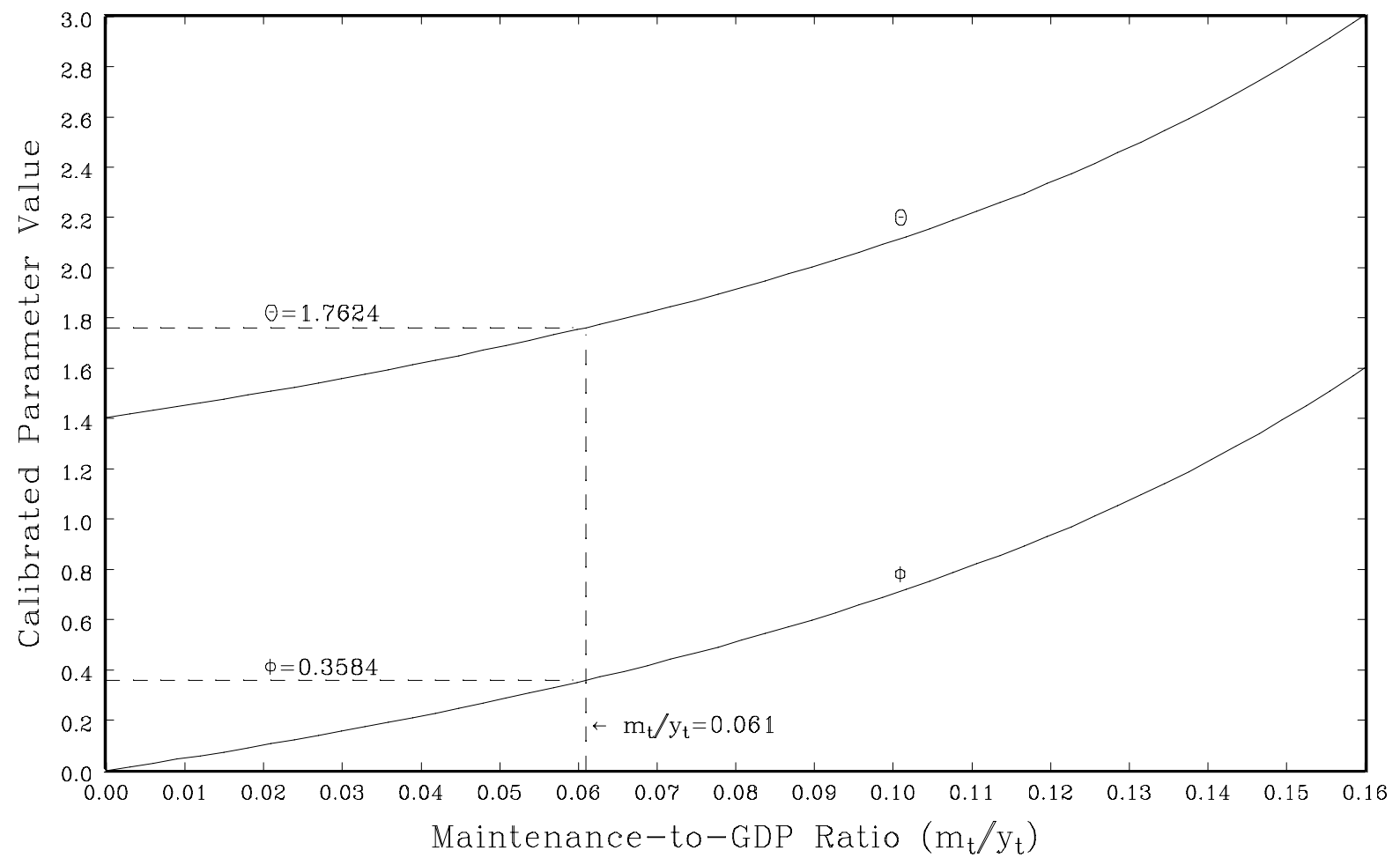

